\title{
Pervasive Intelligent Decision Support System - Technology Acceptance in Intensive Care Units
}

\author{
Filipe Portela ${ }^{1}$, Jorge Aguiar ${ }^{1}$, Manuel Filipe Santos ${ }^{1}$, \\ Álvaro Silva ${ }^{2}$, and Fernado Rua ${ }^{2}$ \\ ${ }^{1}$ Algoritmi Center, University of Minho, Guimarães, Portugal \\ cfp@dsi.uminho.pt, jorge.phena@gmail.com, mfs@dsi.uminho.pt \\ ${ }^{2}$ Intensive Care Unit, Centro Hospitalar do Porto, Portugal \\ moreirasilva@clix.pt, fernandorua.sci@hgsa.min-saude.pt
}

\begin{abstract}
Intensive Care Units are considered a critical environment where the decision needs to be carefully taken. The real-time recognition of the condition of the patient is important to drive the decision process efficiently. In order to help the decision process, a Pervasive Intelligent Decision Support System (PIDSS) was developed. To provide a better comprehension of the acceptance of the PIDSS it is very important to assess how the users accept the system at level of usability and their importance in the Decision Making Process. This assessment was made using the four constructs proposed by the Technology Acceptance Methodology and a questionnaire-based approach guided by the Delphi Methodology. The results obtained so far show that although the users are satisfied with the offered information recognizing its importance, they demand for a faster system.
\end{abstract}

Keywords: TAM, INTCare, Technology Acceptance, Intensive Care, Decision Support System, Pervasive, Technology Assessment.

\section{Introduction}

Decision making in Intensive Medicine (IM) is a crucial process because deals with critical condition patients. Nothing can fail and if something wrong happens the patient can die. It is a specific area of Medicine and their knowledge it is practiced in the Intensive Care Units (ICU). ICU is recognized as a critical environment where the decision needs to be performed fast and with a high level of accuracy [1]. In the ICU the patient care is always the main concern and tasks like is patient documentation are relegated for a second plane [2]. The introduction of intelligent decision support system (IDSS) in the support of decision process is claimed by many of the nurses and physicians which work in ICU. This type of support can be addressed by a pervasive system which operates automatically and in real-time. This system can give to the ICU staff a better comprehension about the patient condition and at the same time predict future situations. INTCare is framed in this type of system. It is a system developed by this research team and which has as main goal the prediction of the patient organ failure and patient outcome in real-time for the next 24 hours. With the 
development of the project, other types of sources were deepened and as result some new knowledge were obtained. Currently, INTCare it is considered by the ICU staff a very useful and complete platform, being composed by a set of pertinent information for the Decision Making Process (DMP). To this work, a list of requirements was defined based on the needs of ICU and the goal to make the system more suitable to the environment. They may be summarized as:

R1. To implement an online data acquisition component;

R2. To make available the laboratory results in an open format;

R3. To allow an open access to prescriptions, interventions and therapeutics;

R4. To dematerialise the nursing records;

R5. To integrate the main systems used in ICU in a single platform;

R6. Develop an automatic system to process and transforming the data.

Taking advantage of the modifications introduced (R1 to R6) it is possible to determine automatically and in real-time, using online learning:

a) ICU medical scores [3];

b) ICU critical events [4];

c) Probability of occur an organ failure probability and patient die [5].

In order to assess the results achieved, the technology, the INTCare functionalities and their importance to ICU, a questionnaire was developed. This questionnaire is based in the Technology Acceptance Methodology (TAM) [6] and it is concerned to the evaluation of four aspects: perceived usefulness (PU), perceived ease of use (PEOU), behavioural intention (BI) and use behaviour (UB). Despite of the questionnaire used be composed by a high number of questions, in this paper only are presented the TAM results associated to the decision making process, i.e., the results related to DMP.

This paper is divided in seven sections. The first and second sections introduce the work and make an overview of the concepts and work previous performed. The third section presents the improvements attained in the Intensive Care according to INTCare features. Then the fourth section introduces the PIDSS at the level of results achieved. The fifth and sixth sections are related to the TAM; the questionnaire performed and results achieved. Finally, some remarks and future work are considered.

\section{Background}

During 2009 when this project started the ICU information system was composed by a set of information silos. The ICU professionals need to access to more than five hospital applications to obtain important information and to make their decisions. Now with the introduction of INTCare they have the most important information available in the Electronic Nursing Record (ENR) and they can obtain new knowledge automatically moments after the patient documentation. This situation only was possible with the modification made by INTCare project and the introduction of new knowledge into the ICU DMP. 


\subsection{INTCare}

INTCare $[7,8]$ is an IDSS to predict organ failure and patient outcome for the next 24 hours in real-time using online learning. This system is result of a research project. The research and modifications done allowed to obtain new types of data in an electronically format and in real-time $[9,10]$. The new reality and the new environment created [11] allow for obtaining new knowledge fundamental to the decision process predicting patient condition, scoring the ICU measures and tracking critical events automatically and in real-time. The data is obtained through a streaming process and the knowledge attained is disseminated in situated devices.

\subsection{Decision Making Process in Intensive Care Units}

Making decisions in ICU is a complicated and danger process, because all tasks need to be performed quickly and accurately [1]. The ICU professionals deal with patients in serious life-risk. The use of technologies to support this type of process is welcome [2] however, normally this type of systems aren't helping, i.e., don't present the accurate information in the right time and in the right place. These types of situations complicate the decision process. At the same time, there is a problem associated to the patient documentation because it is always relegated to a second place. In order to overcome this situation some modifications were made in the ICU environment [11] and in the DMP.

\subsection{Technology Acceptance Methodology and Delphi Methodology}

The evaluation of a technology application is crucial to comprehend its suitability in a specific environment and also to measure the satisfaction level of its users. One of the most used models in this area is the Technology Acceptance Methodology. "TAM is adapted from the Theory of Reasoned Action (TRA) model which describes human behaviours in a specific situation" [12]. The main purpose of TAM is to present an approach to study the effects of external variables towards people's internal beliefs, attitudes, and intentions [6]. This model is also important because it gives an understanding about the acceptance of the decision support by the ICU staff and how can be useful in the course of their daily work. The goals of TAM can be achieved by using methodologies based on questionnaires. As a support tool it is important to use some aspects/characteristic of the Delphi method. The principles of the Delphi method involves the use of questionnaires being one of its key features [13] the preservation of anonymity of the participants. A questionnaire was prepared by a coordination team, composed by professionals of ICU and Information System, and sent to a set of participants (a group of experts from the ICU nurses team). The questionnaire was prepared taking into account the constructs of TAM $[14,15]$. The correlations of the answers were evaluated through the Kendall's tau $(\tau)$ coefficient. Kendall's tau is a measure of rank correlation. The values range from -1 (inversion) to +1 (perfect agreement). A value of zero indicates the absence of association. 


\subsection{Related Work - Results Obtained in the First Approach}

In order to make a first assessment of the technology, a quick and short questionnaire was produced [16]. The main goal was to have a first idea about the usefulness and ease of use of the system in superficial way. This questionnaire was the starting point of the second questionnaire (with tam) and it had a short scope. The questions were divided into two groups: Functional characteristics (data registration, information access and proactive performance) and Technical characteristics (efficient consulting, response time, system security, usability, and interoperability). Finally, a last question evaluate if the system suits the needs. The questionnaire was answered using a fivescale metric: Does not meet / in complete disagreement ( $<20 \%$ of cases) (1) until fully meet / fully agree (> 80\%) (5) [16]. In terms of results only two questions were answered with less than 4 points: one question about the registration system and other question about the understanding of the system and their benefits.

Concluding, in the first phase of assessment the users revealed to be comfortable with the system. These results motivated: i) to continue the development of the project; and ii) perform a more extensive and deep questionnaire having the objective to understand the technology acceptance by the ICU users.

\section{Research Propose - Improvements Introduced in ICU}

The improvements made are according to the INTCare requirements (R1 to R6) defined in the introduction and can be summarized as:

\subsection{Data Acquisition System (R1)}

The first requirement was resolved with the implementation of a gateway. The gateway is connected to the vital signs monitors, reads the patient information and stores it on a database through the data acquisition agent. This is an autonomous process and it is always in a continuous collecting process (streaming).

In this phase two problems appear: missing patient identification (PID) and the acquisition of bad values. To overcome these problems two triggers were developed. One trigger to verify on the Electronic Health Record (EHR) system the PID of the patient admitted in bed where the values are provided and other trigger to validate the values. This second process uses the range of values pre-defined by ICU. Both the procedures are executed in the moment of the values are collected.

\subsection{Laboratory (R2)}

Regarding to the laboratory, an effort was made to have the lab results in an open format, i.e., accessible electronically and able to be handled without restrictions. The main objective was making the results available for ICU immediately after the patient exams are concluded. This change gives the possibility to have the results in a comparative format during the patient stay in ICU. Those exams have different types and are executed by different services and at different hours [16]. 


\subsection{Open Access to Prescriptions (R3)}

In this point the objective was deal with pharmacy and to study the possibility to construct an easy access to patient prescriptions. These prescriptions were totally controlled by pharmacy and whenever someone needed to consult the patient therapeutic plan had to open a too slow platform. Now, the interaction between the pharmaceutical system and ENR is made by an agent. Periodically, the ENR agent sends a request to the pharmacy drugs system and then, the requested data is sent to a database table [16].

\subsection{Electronic Nursing Record (R4 and R5)}

Electronic Nursing Record (ENR) is a platform that it was developed with the objective to receive all medical data and put it available electronically and in real-time to the physicians and nurses in an hourly mode. ENR can achieve two requirements because being it electronic can dematerialize the processes and due the interoperability mode can interoperate with all of others ICU data sources. Currently the ICU staff using the ENR has more vital information about the patient in order to help to make their decisions. ENR is a touch and web-based platform and it is composed by different screens. The data is grouped by the information provenance.

\subsection{Automatic Data Processing and Transformation (R6)}

After obtain all the essential data to the decision making process it was necessary introduce new features to the transformation process. The uses of intelligent agents allowed automate the whole process. Now the tasks associated to data preparation process are performed automatically and in real-time without human effort. These changes increase the speed in getting new knowledge being they useful and available in the right time, i.e., in the moment of the decision is taken.

\section{Pervasive Intelligent Decision Support System}

A pervasive intelligent Decision Support System (PIDSS) is recognized as a system that helps the decision making process and it is accessible anywhere and anytime. In the health care arena there are two concepts related to PIDSS as is the pervasive healthcare and the pervasive computing [17]. Due their pervasive features, INTCare can produce three different types of knowledge. This knowledge is available anywhere and anytime.

\subsection{ICU Medical Scores}

The objective of PIDSS component is to behave as an Intelligent Scoring System (ISS). The ISS [3] is incorporated into the Electronic Nursing Record (ENR). Nowadays, the ICU professionals can record and consult the scores in real-time. 
This application allows for the automatic calculation in real-time of a set of scores: simplified acute physiology score (SAPS) II [18], SAPSIII [19], Sequential Organ Failure Assessment score (SOFA) [20], Glasgow Coma Score (GSC) [21], Therapeutic Intervention Scoring System (TISS-28) [22] and Modified Early Warning Score (MEWS) [23]. At the same time it is possible to analyze the patient evolution in terms of the scores through interactive graphs (in a hourly and daily base). As mentioned before [3]: this approach makes possible to provide a set of scores calculated / updated in real time. The ISS proposed processes automatically the scores and adapts the results according to the new values collected generating new knowledge. The main gains in using this approach can be summarized as:

- The data acquisition, scores calculation and results are made in real-time;

- All values are considered - no missing values;

- The data is displayed in a new way - real-time charts to compare trends;

- Less human intervention in the scores calculation - less errors;

- The scores are available anywhere and anytime;

- Help decision making process through a continuous scores monitoring.

\subsection{ICU Critical Events}

Critical Events (CE) are very important to the development of Data Mining (DM) models. In order to develop DM models in a real setting it was necessary to define procedures to automatically compute CE for five variables: Urine Output (Diuresis), Blood Pressure, Heart Rate, Respiratory and Temperature [4]. The procedure calculates according some rules the number and elapsed time of an event. Then, the value is characterized as critical or not. As result it is possible determine a number of critical events for the patient by hour and category [4]. In complement it is calculated the Accumulated Critical Events (ACE) [4]. The CE system is composed by a grid and a system similar to a traffic light. This system is used as a way to alert about the patient condition. The grid shows: the number of critical events by hour, the number of ACE, the time in critical event by hour and the total time in critical event. The implementation of this new approach allows to the physicians have better understanding of the patient's condition.

\subsection{Ensemble Based Models}

Data Mining (DM) is the centre of the PIDSS. The objective of DM system is to predict the patient organ failure (cardiovascular, hepatic, coagulation, respiratory and renal) and patient outcome for the next hour. To achieve this goal an ensemble DM was developed. To evaluate the ensemble three measures were considered: Sensibility, Accuracy and Terror. For each measure the average of 10 runs was taken. The selected models are used only if they satisfy the following conditions (quality measure): Total Error $<=40 \%$; sensitivity $>=85 \%$ and Accuracy $>=60 \%$. The use of ensemble helps to choose the best model in the cases where more than one model 
presents good results. From the six targets, only three satisfy the quality measures defined: outcome, cardiovascular and coagulation. The low level of results verified in the other targets it is associated to the dynamic characteristics of the environment. Currently, it is possible induce DM models in real-time using online-learning and an ensemble approach in order to adapt the predictive models automatically. The doctors can use the predictions to save lives and avoid complicated situations to the patient.

\section{Technology Acceptance Questionnaires}

For this study it was elaborated a questionnaire based on the four constructs of TAM 3. This questionnaire was elaborated by taking into account some scientific articles that report similar processes of technological implementation and are framed in the hospital environment and the first results obtained. It means they were aggregated into several groups to represent all the aspects of TAM. The main purpose is to obtain a better understanding about the user's intentions on the use of this system in the long run as well as the functionality for them. The questionnaire is composed by 96 questions. However, in this paper only were considered the questions related to the decision process. In this questionnaire was applied the Likert Scale [24] to evaluate the results. This scale was chosen because the use of short scales (scales that goes between three and four) can better constrain results into close type of answers such as a simple yes or no; and secondly, by applying a higher scale this could fall into a dispersion of results that lead the answers to inaccurate results. As a consequence the chosen scale follows a range from one to five points similar to the used in the previous work / questionnaire. It allows for giving two values for each side and at the same time finding a neutrality point [24]. The considered levels are the following:

1) Not satisfies/in complete disagreement ( $<20 \%$ of cases);

2) Satisfies a bit/in some level of disagreement (20-40\%);

3) Satisfies/under some level of agreement (40-60\%);

4) Satisfies a lot/strongly agreement (60-80\%);

5) Satisfies completely/full agreement $(>80 \%)$.

The level of results collected from this questionnaire vary by the fact of the participant answer in a properly manner (with consciousness) or not. The answers always depend on the goodwill of each participant by answering in a balanced way to the questions of a certain group. This hypothesis does not verify when the participant evaluates a specific characteristic as a whole and gives the same answer to the group questions. To avoid this problem it was added to the questionnaire three screening questions to understand the level of the user's consciousness (e.g. 3+2). Table 1 crosses the questions with the constructs: Perceived Usefulness (PU); Perceived Ease of Use (PEOU); Behavioural Intention (BI); Use Behaviour (UB). 
Table 1. Questions of Functional Characteristics

\begin{tabular}{|c|c|c|c|c|c|}
\hline \multicolumn{2}{|c|}{ Functional Characteristics } & \multicolumn{3}{|c|}{ PU РEOL BI } & \multirow{2}{*}{$\begin{array}{c}\boldsymbol{U B} \\
\mathrm{X}\end{array}$} \\
\hline 1.1 & It allows the efficient registration of the information? & & $\mathrm{X}$ & & \\
\hline 1.2 & It allows obtaining efficient information for decision support? & & $\mathrm{X}$ & & $\mathrm{X}$ \\
\hline 1.3 & It shows the prevision of Adverse Effects in an efficacy way? & & $\mathrm{X}$ & $\mathrm{X}$ & \\
\hline 1.4 & It shows usefulness when predicts the Scores? & & $\mathrm{X}$ & $\mathrm{X}$ & \\
\hline 1.5 & It improves the proactive performance of the professionals? & $\mathrm{X}$ & $\mathrm{X}$ & $\mathrm{X}$ & $\mathrm{X}$ \\
\hline 1.6 & It allows tasks to be performed with greater precision? & $\mathrm{X}$ & $\mathrm{X}$ & & \\
\hline 1.7 & Can help to mitigate situations of an excessive workload? & $\mathrm{X}$ & $\mathrm{X}$ & $\mathrm{X}$ & $\mathrm{X}$ \\
\hline 1.8 & Can allow a major control of several tasks? & $\mathrm{X}$ & $\mathrm{X}$ & & $\mathrm{X}$ \\
\hline 1.9 & $\begin{array}{l}\text { Can help to have a better decision making based in best } \\
\text { evidences? }\end{array}$ & $\mathrm{X}$ & $\mathrm{X}$ & & $\mathrm{X}$ \\
\hline 1.10 & Potentiates an improvement delivery of patient's health care? & $\mathrm{X}$ & $\mathrm{X}$ & & $\mathrm{X}$ \\
\hline 1.11 & It allows monitoring the patient's condition? & $\mathrm{X}$ & $\mathrm{X}$ & & $\mathrm{X}$ \\
\hline 1.12 & It promotes automating tasks? & $\mathrm{X}$ & $\mathrm{X}$ & & $\mathrm{X}$ \\
\hline 1.13 & $\begin{array}{l}\text { It allows answering with the appropriate information to perform } \\
\text { the task? }\end{array}$ & $\mathrm{X}$ & $\mathrm{X}$ & $\mathrm{X}$ & $\mathrm{X}$ \\
\hline Techni & ical Characteristics & $P U$ & 'EOU & $B I$ & $\boldsymbol{U B}$ \\
\hline 2.1 & Can promote quality of the information? & $\mathrm{X}$ & & $\mathrm{X}$ & $\mathrm{X}$ \\
\hline 2.2 & Can access to information quickly? & $\mathrm{X}$ & & & $\mathrm{X}$ \\
\hline 2.3 & It allows access to information in a secure way? & $\mathrm{X}$ & $\mathrm{X}$ & & $\mathrm{X}$ \\
\hline 2.4 & Can operate simultaneously with other hospital systems? & $\mathrm{X}$ & $\mathrm{X}$ & $\mathrm{X}$ & $\mathrm{X}$ \\
\hline 2.5 & $\begin{array}{l}\text { Can facilitate an operation by having a tactile interface beside to } \\
\text { patient's beds? }\end{array}$ & $\mathrm{X}$ & $\mathrm{X}$ & $\mathrm{X}$ & $\mathrm{X}$ \\
\hline 2.6 & $\begin{array}{l}\text { It allows an efficient use based on the available technical } \\
\text { support? }\end{array}$ & $\mathrm{X}$ & $\mathrm{X}$ & $\mathrm{X}$ & $\mathrm{X}$ \\
\hline 2.7 & $\begin{array}{l}\text { Evaluate the potential of each registration presented on the } \\
\text { Intervention's panel: }\end{array}$ & & & & \\
\hline 2.71 & $\begin{array}{l}\text { Can facilitate obtaining information regarding the realized } \\
\text { interventions? }\end{array}$ & & $\mathrm{X}$ & & \\
\hline 2.72 & $\begin{array}{l}\text { Can facilitate obtaining information regarding the therapeutic } \\
\text { attitudes? }\end{array}$ & & $\mathrm{X}$ & & \\
\hline 2.73 & Graphic aspect? & & $\mathrm{X}$ & & \\
\hline 2.74 & Registration of the work plan? & & $\mathrm{X}$ & & \\
\hline 2.75 & Utility of TISS28? & $\mathrm{X}$ & $\mathrm{X}$ & $\mathrm{X}$ & $\mathrm{X}$ \\
\hline 2.76 & Graphic aspect of TISS28? & $\mathrm{X}$ & $\mathrm{X}$ & $\mathrm{X}$ & \\
\hline 2.77 & Global Evaluation of TISS28 & $\mathrm{X}$ & $\mathrm{X}$ & $\mathrm{X}$ & $\mathrm{X}$ \\
\hline 2.8 & $\begin{array}{l}\text { Evaluate the potential of each registration presented on the } \\
\text { Score's panel: }\end{array}$ & & & & \\
\hline 2.8 .1 & $\begin{array}{l}\text { The records made automatically, present similar values } \\
\text { relatively to the manuscripts ones? }\end{array}$ & $\mathrm{X}$ & $\mathrm{X}$ & & \\
\hline 2.8.2 & Utility of SOFA CHART? & $\mathrm{X}$ & $\mathrm{X}$ & $\mathrm{X}$ & $\mathrm{X}$ \\
\hline 2.8 .3 & Utility of GLASGOW CHART? & $\mathrm{X}$ & $\mathrm{X}$ & $\mathrm{X}$ & $\mathrm{X}$ \\
\hline 2.8 .4 & Graphic aspect is intuitive? & $\mathrm{X}$ & $X$ & $\mathrm{X}$ & $\mathrm{X}$ \\
\hline 2.8.5 & $\begin{array}{l}\text { The graphics can help to a better understanding of the real } \\
\text { patient's condition? }\end{array}$ & $\mathrm{X}$ & $\mathrm{X}$ & $\mathrm{X}$ & $\mathrm{X}$ \\
\hline 2.8 .6 & $\begin{array}{l}\text { By using the automation registration of Scores it facilitates the } \\
\text { registration of SAPS II? }\end{array}$ & $\mathrm{X}$ & & $\mathrm{X}$ & $\mathrm{X}$ \\
\hline 2.8.7 & $\begin{array}{l}\text { By using the automation registration of Scores it facilitates the } \\
\text { registration of SAPS III? }\end{array}$ & $\mathrm{X}$ & & $\mathrm{X}$ & $\mathrm{X}$ \\
\hline
\end{tabular}


Table 1. (continued)

\begin{tabular}{|c|c|c|c|c|c|}
\hline 2.8 .8 & $\begin{array}{l}\text { By using the automation registration of Scores it facilitates the } \\
\text { registration of GLASGOW? }\end{array}$ & $\mathrm{X}$ & & $\mathrm{X}$ & $\mathrm{X}$ \\
\hline 2.8 .9 & Global Evaluation of Scores? & $\mathrm{X}$ & $\mathrm{X}$ & $\mathrm{X}$ & $\mathrm{X}$ \\
\hline 2.9 & $\begin{array}{l}\text { Evaluate the potential of each registration presented on the } \\
\text { Vital Sign's panel: }\end{array}$ & & & & \\
\hline 2.9.1 & Utility of information? & $\mathrm{X}$ & $\mathrm{X}$ & $\mathrm{X}$ & \\
\hline 2.9.2 & Utility of consulting information (hourly, daily, continuous)? & $\mathrm{X}$ & $\mathrm{X}$ & $\mathrm{X}$ & \\
\hline 2.9 .3 & Graphic aspect? & $\mathrm{X}$ & $\mathrm{X}$ & $\mathrm{X}$ & \\
\hline 2.9 .4 & MEWS - Utility of system? & $X$ & $\mathrm{X}$ & $\mathrm{X}$ & \\
\hline 2.9 .5 & Adverse events - Utility of system? & $\mathrm{X}$ & & $\mathrm{X}$ & $\mathrm{X}$ \\
\hline 2.9 .6 & The early warning system for Adverse Events is useful? & $\mathrm{X}$ & $\mathrm{X}$ & & \\
\hline 2.9.7 & Graphic aspect? & & $\mathrm{X}$ & & \\
\hline 2.9 .8 & Global evaluation of the vital signs? & $\mathrm{X}$ & $\mathrm{X}$ & $\mathrm{X}$ & $\mathrm{X}$ \\
\hline 2.10 & It is advantageous to use this system in intensive care units? & $\mathrm{X}$ & & $\mathrm{X}$ & $X$ \\
\hline
\end{tabular}

\section{Results}

After collecting answers from 14 questionnaires sent by email (35\% total number of nurses in ICU) an analysis of the results was performed. First a processing was done to avoid invalid or inconsistent answers given by the participants. Then was noticed that only one participant out of the 14 nurses answered the questionnaire in an inconsistent way for the proposed questions. This situation leaded to only consider 13 surveys. Table 2 presents the technology experience of the respondents.

Table 2. Level of experience in Information Technology

\begin{tabular}{llr}
\hline Question & Answer & Percentage \\
\hline What is your experience in & Less than 2 hours/day & $0 \%$ \\
technology - How much time & Between 2 to 4 hours/day & $57 \%$ \\
do you spend at the computer & More 4 hours/day & $36 \%$ \\
\hline & Full Autonomy & $62 \%$ \\
& Rarely need technical support (less than 3 & $38 \%$ \\
Type of User? & times/month) & $0 \%$ \\
& Need regular technical support & $62 \%$ \\
& Application of production staff (email, text & $31 \%$ \\
& processing, spreadsheet) & $77 \%$ \\
Uses computer preferably for? & Handling/Consulting administrative information & $8 \%$ \\
& Handling/Consulting clinical information & \\
& Handling/Consult management information &
\end{tabular}




\subsection{Respondent Analysis}

For a better perception of the answers made by each respondent, one analysis (average and mode) was carried out by the person questioned and TAM construct (fig 1 to 4 ). In this analysis, the persons (X axis) are represented by numbers (1 to 13).

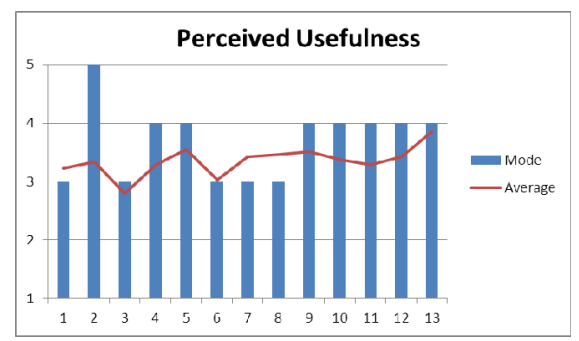

Fig. 1. Evaluation of PU

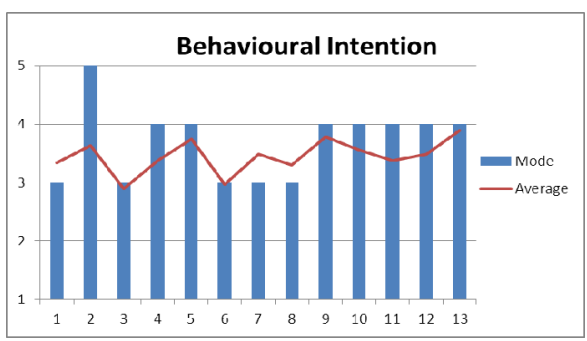

Fig. 3. Evaluation of BI

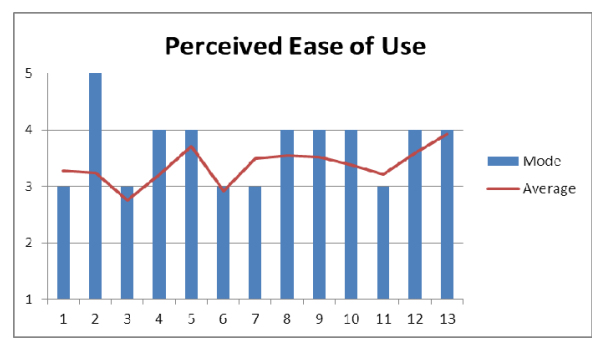

Fig. 2. Evaluation of PEOU

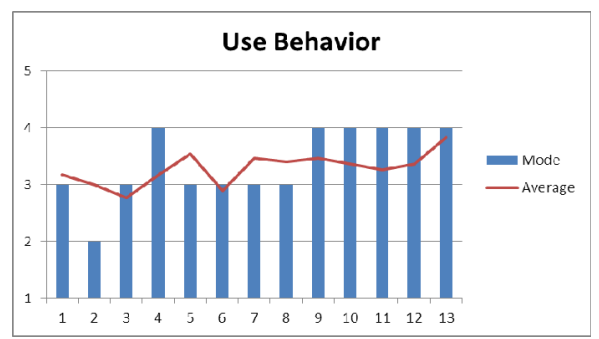

Fig. 4. Evaluation of UB

At a high level of analysis, in figures 1,2 and 3, is possible to observe that the second person answered most of the questions with 5 values; however the average is between 3 and 4 points. This means that this person is quite pleased with some aspects of the system and not with others. In general the evaluations are above 3 points. At same time some correlations techniques were used to understand if the users are in accordance with the answers. In a global way they are in relative accordance in some of the questions, being the overall Kendall's tau: 0,158224.

\subsection{Question Analysis}

In this sub-section, instead of doing an analysis by respondent, an analysis was made for each one of the question and TAM 3 construct. In the $\mathrm{Y}$ axis they are the possible answers of the questionnaire (1-5) and in the $\mathrm{X}$ axis they are the questions numbers. 


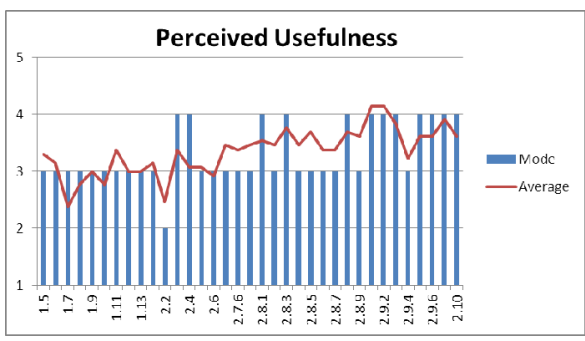

Fig. 5. Analysis for questions (PU)

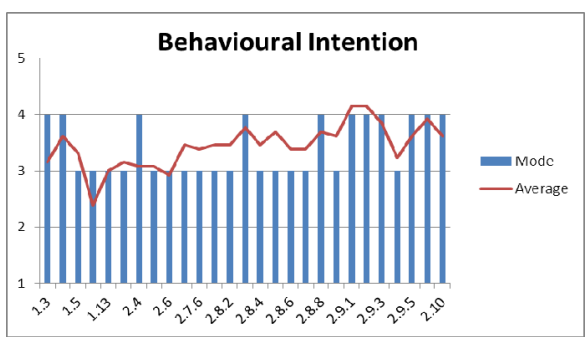

Fig. 7. Analysis for questions (BI)

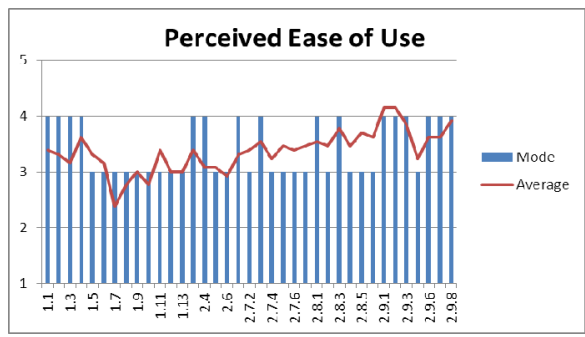

Fig. 6. Analysis for questions (PEOU)

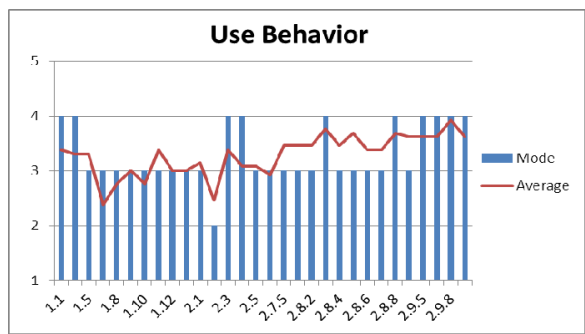

Fig. 8. Analysis for questions (UB)

In figure 5 and 8 it should be stressed that question 2.2 has a lowest score. On the other hand, the average of the answers for the questions related to these constructs is situated between 2 and 4 points. This result means that sometimes it is difficult to have access to the data. This happens due to hospital connectivity problems in the network. This problem represents the biggest barrier to the success of INTCare. In Figure 6 and 7, the vast majority of the answers of the questions to this constructs were stood by 3 points.

\subsection{Global Analysis by Question}

A global analysis was done in order to understand the best features, the average, the mode and the standard deviation (stdev) for each one of constructs. Table 3 offers a quick view of the answers obtained by the questionnaires. This table shows that the ICU staffs are satisfied with the system. All the constructs present positive results being the best, the Perceived Ease of Use and the worst, the Use behaviour.

Table 3. Summary of mode and average for each construct and analysis overall

\begin{tabular}{c|ccccc}
\hline & $\boldsymbol{P U}$ & $\boldsymbol{P E O U}$ & $\boldsymbol{B L}$ & $\boldsymbol{U} \boldsymbol{B}$ & Overall \\
\hline Mode & 3 & 3 & 3 & 3 & 3 \\
Average & 3,35 & 3,67 & 3,44 & 3,28 & 3,36 \\
Stdev & 0,18 & 0,21 & 0,20 & 0,21 & 0,21 \\
Min & 1 & 1 & 1 & 1 & 1 \\
Max & 5 & 5 & 5 & 5 & 5 \\
\hline
\end{tabular}


Table 4 offers a quick understanding of each construct. This table presents the three best and the three worst results. In the positive side they are some information (charts) to the decision process and the importance that the graphics have in order to have a better understand of the patient condition. This characteristic has as average (avg) 4.15. In the opposite side they are some functional characteristics. It is possible to observe that there are two negative characteristics (1.7 and 2.2). Both of them are related to the system speed. Despite all that, only one question has as mode 2 points. All of the other questions have a mode between the 3 and 4 points.

Table 4. The three best and worst results

\begin{tabular}{l|ccc|ccc|crc|crc}
\hline & PU & Mode & Avg & PEOU Mode & Avg & BI & Mode & Avg & UB & Mode & Avg \\
\hline \multirow{2}{*}{ Best } & $\underline{2.9 .1}$ & 4 & $\mathbf{4 , 1 5}$ & $\underline{2.9 .1}$ & 4 & $\mathbf{4 , 1 5}$ & $\underline{2.9 .1}$ & 4 & $\mathbf{4 , 1 5}$ & $\underline{2.9 .8}$ & 4 & 3,92 \\
Results & $\underline{2.9 .2}$ & 4 & $\mathbf{4 , 1 5}$ & $\underline{2.9 .2}$ & 4 & $\mathbf{4 , 1 5}$ & $\underline{2.9 .2}$ & 4 & $\mathbf{4 , 1 5}$ & $\underline{2.8 .3}$ & 4 & 3,77 \\
& $\underline{2.9 .8}$ & 4 & 3,92 & $\underline{2.9 .8}$ & 4 & 3,92 & $\underline{2.9 .8}$ & 4 & 3,92 & $\underline{2.8 .5}$ & 3 & 3,69 \\
\hline \multirow{2}{*}{ Worst } & $\underline{1.7}$ & 3 & 2,38 & $\underline{1.7}$ & 3 & 2,38 & $\underline{1.7}$ & 3 & 2,38 & $\underline{1.7}$ & 3 & 2,38 \\
Results & $\underline{2.2}$ & 2 & 2,46 & $\underline{1.8}$ & 3 & 2,77 & $\underline{\underline{2.6}}$ & 3 & 2,92 & $\underline{1.8}$ & 3 & 2,77 \\
& $\underline{1.8}$ & 3 & 2,77 & $\underline{1.10}$ & 3 & 2,77 & $\underline{1,13}$ & 3 & 3 & $\underline{1.10}$ & 3 & 2,77 \\
\hline
\end{tabular}

\section{Conclusions and Future Work}

First, it should be noted that the initial objective proposed regarding to the junction of the Technology Acceptance Model (TAM 3) with the Delphi's method in order to evaluate the acceptance by users, their perceptions and the impact on the INTCare's system usage behaviour, it is totally innovative and can be considered a success. This is the first approach to assess the impact of such type of solutions in ICU environment.

In order to understand the acceptance it is possible to conclude that the ICU staff it is very comfortable with the system INTCare. They pointed the data access as the biggest problem and the utility of the information generated for the decision process as the biggest gain. The user acceptance was very positive (average upper than 3 points) for the four constructs assessed: Perceived Usefulness, Perceived ease of use, Behavioral Intention and Usage Behaviour.

Concluding, the ICU professionals are receptive to the INTCare system and to the new knowledge provided because it can help them in the decision making process.

The results obtained by the questionnaires allow for some concluding remarks:

These results encourage further development and optimization of the solutions designed, as well as a deeper assessment of all the resources available;

$\checkmark$ It is required an improvement of physical resources (e.g. memory, hardware) of the ICU.

Acknowledgements. This work is supported by FEDER through Operational Program for Competitiveness Factors - COMPETE and by national funds though FCT - Fundação para a Ciência e Tecnologia in the scope of the project: FCOMP-010124-FEDER-022674. 
The authors would like to thank FCT (Foundation of Science and Technology, Portugal) for the financial support through the contract PTDC/EIA/72819/ 2006. The work of Filipe Portela was supported by the grant SFRH/BD/70156/2010 from FCT.

\section{References}

[1] Baggs, J.G., Norton, S.A., Schmitt, M.H., Dombeck, M.T., Setters, C.R., Quinn, J.R.: Intensive care unit cultures and end-of-life decision making. Journal of Critical Care 22, 159-168 (2007)

[2] Mador, R.L., Shaw, N.T.: The impact of a Critical Care Information System (CCIS) on time spent charting and in direct patient care by staff in the ICU: a review of the literature. International Journal of Medical Informatics 78, 435-445 (2009)

[3] Portela, F., Santos, M.F., Machado, J., Silva, Á., Rua, F., Abelha, A.: Intelligent Data Acquisition and Scoring System for Intensive Medicine. In: Böhm, C., Khuri, S., Lhotská, L., Renda, M.E. (eds.) ITBAM 2012. LNCS, vol. 7451, pp. 1-15. Springer, Heidelberg (2012)

[4] Filipe Portela, P.G., Santos, M.F., Silva, Á., Rua, F.: Intelligent and Real Time Data Acquisition and Evaluation to Determine Critical Events in Intensive Medicine. In: HCist 2012 - International Conference on Health and Social Care Information Systems and Technologies, Portugal (2012)

[5] Filipe Portela, F.P., Santos, M.F.: Data Mining Predictive Models For Pervasive Intelligent Decision Support In Intensive Care Medicine. Presented at the KMIS 2012 nternational Conference on Knowledge Management and Information Sharing, Barcelona (2012)

[6] Chooprayoon, V., Fung, C.C.: TECTAM: An Approach to Study Technology Acceptance Model (TAM) in Gaining Knowledge on the Adoption and Use of E-Commerce/EBusiness Technology among Small and Medium Enterprises in Thailand (2010)

[7] Santos, M.F., Portela, F., Vilas-Boas, M., Machado, J., Abelha, A., Neves, J.: INTCARE - Multi-agent approach for real-time Intelligent Decision Support in Intensive Medicine. In: 3rd International Conference on Agents and Artificial Intelligence (ICAART), Rome, Italy (2011)

[8] Gago, P., Santos, M.F., Silva, Á., Cortez, P., Neves, J., Gomes, L.: INTCare: a knowledge discovery based intelligent decision support system for intensive care medicine. Journal of Decision Systems (2006)

[9] Portela, F., Gago, P., Santos, M.F., Silva, A., Rua, F., Machado, J., et al.: Knowledge Discovery for Pervasive and Real-Time Intelligent Decision Support in Intensive Care Medicine. Presented at the KMIS 2011- International Conference on Knowledge Management and Information Sharing, Paris, France (2011)

[10] Portela, F., Santos, M., Vilas-Boas, M., Rua, F., Silva, Á., Neves, J.: Real-time Intelligent decision support in intensive medicine. Presented at the KMIS 2010- International Conference on Knowledge Management and Information Sharing, Valência, Espanha (2010)

[11] Portela, F., Santos, M.F., Silva, Á., Machado, J., Abelha, A.: Enabling a Pervasive approach for Intelligent Decision Support in Critical Health Care. Presented at the HCist 2011 - International Workshop on Health and Social Care Information Systems and Technologies, Algarve, Portugal (2011)

[12] Fishbein, M., Ajzen, I.: Belief, attitude, intention and behaviour: An introduction to theory and research. Addison-Wesley (1975) 
[13] Zackiewicz, M., Salles Filho, S.: Technological Foresight-Um instrumento para política científica e tecnológica. Parcerias Estratégicas 6 (2010)

[14] Venkatesh, V., Bala, H.: Technology acceptance model 3 and a research agenda on interventions. Decision Sciences 39, 273-315 (2008)

[15] Venkatesh, V., Davis, F.D.: A theoretical extension of the technology acceptance model: Four longitudinal field studies. Management Science, 186-204 (2000)

[16] Filipe Portela, M.F.S., Machado, J., Abelha, A., Neves, J., Silva, Á., Rua, F.: Intelligent Decision Support in Intensive Care -Towards Technology Acceptance. Presented at the 26th European Simulation and Modelling Conference - ESM 2012, Essen, Germany (2012)

[17] Varshney, U.: Pervasive Healthcare Computing: EMR/EHR, Wireless and Health Monitoring. Springer-Verlag New York Inc. (2009)

[18] Le Gall, J.R., Lemeshow, S., Saulnier, F.: A new Simplified Acute Physiology Score (SAPS II) based on a European/North American multicenter study. JAMA 270, 29572963 (1993)

[19] Metnitz, P.G.H., Moreno, R.P., Almeida, E., Jordan, B., Bauer, P., Campos, R.A., et al.: SAPS 3-From evaluation of the patient to evaluation of the intensive care unit. Part 1: Objectives, methods and cohort description. Intensive Care Medicine 31, 1336-1344 (2005)

[20] Vincent, J., Mendonça, A., Cantraine, F., Moreno, R., Takala, J., Suter, P., et al.: Use of the SOFA score to assess the incidence of organ dysfunction/failure in intensive care units: Results of a multicenter, prospective study. Critical Care Medicine 26, 1793-1800 (1998)

[21] Jones, C.: Glasgow coma scale. AJN, The American Journal of Nursing 79, 1551 (1979)

[22] Reis Miranda, D., de Rijk, A., Schaufeli, W.: Simplified Therapeutic Intervention Scoring System: the TISS-28 items-results from a multicenter study. Critical Care Medicine 24, 64 (1996)

[23] Gardner-Thorpe, J., Love, N., Wrightson, J., Walsh, S., Keeling, N.: The value of Modified Early Warning Score (MEWS) in surgical in-patients: a prospective observational study. Annals of the Royal College of Surgeons of England 88, 571 (2006)

[24] Johns, R.: Likert Items and Scales. Survey Question Bank: Methods Fact Sheet 1 (2010) 